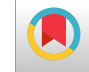

\title{
Liver Transplantation in Progressive Familial Intrahepatic Cholestasis with Normal Gamma-Glutamyl Transferase: Evaluation of Post-transplant Steatosis and Steatohepatitis
}

\author{
Mohammad Hossein Anbardar (iD ${ }^{1,}$, Seyed Mohsen Dehghani $\mathbb{D}^{2}$, Maryam Poostkar ${ }^{3}$ and Seyed Ali \\ Malek-Hosseini $^{4}$ \\ ${ }^{1}$ Department of Pathology, Shiraz Medical School, Shiraz University of Medical Sciences, Shiraz, Iran \\ ${ }^{2}$ Department of Pediatric Gastroenterology and Hepatology, Shiraz University of Medical Sciences, Shiraz, Iran \\ ${ }^{3}$ Student Research Committee, Shiraz University of Medical Sciences, Shiraz, Iran \\ ${ }^{4}$ Department of Surgery, Shiraz Transplant Center, Abualisina Hospital, Shiraz University of Medical Sciences, Shiraz, Iran \\ "Corresponding author: Department of Pathology, Shiraz Medical School, Shiraz University of Medical Sciences, Shiraz, Iran. Email: anbardarm@sums.ac.ir
}

Received 2021 July 27; Revised 2021 September 13; Accepted 2021 September 24.

\begin{abstract}
Background: Progressive familial intrahepatic cholestasis is a disease presenting with severe cholestasis and progressing to the end-stage liver disease later. Liver transplantation is a treatment modality available for progressive familial intrahepatic cholestasis, especially in patients with end-stage liver disease or those who are unsuitable for or have failed biliary diversion.

Objectives: To evaluate clinical and pathological characteristics of progressive familial intrahepatic cholestasis patients who had undergone liver transplantation and to determine post-transplant steatosis and steatohepatitis.

Methods: We evaluated 111 progressive familial intrahepatic cholestasis patients with normal gamma-glutamyl transferase that performed liver transplantation in Shiraz Transplant Center in Iran between March 2000 and March 2017.

Results: The most common clinical manifestations were jaundice and pruritus. Growth retardation and diarrhea were detected in $76.6 \%$ and $42.5 \%$ of the patients. After transplantation, growth retardation was seen in $31.5 \%$ of the patients, and diarrhea in $36.9 \%$ of them. Besides, $29.1 \%$ of the patients died post-transplant. Post-transplant liver biopsies were taken from 50 patients, and 15 (30\%) patients had steatosis or steatohepatitis, five of whom (10\%) had macrovesicular steatosis alone, and 10 (20\%) had steatohepatitis. Only one patient showed moderate bridging fibrosis (stage III), and none of them showed severe fibrosis.

Conclusions: Liver transplantation is the final treatment option for these patients, and it can relieve most clinical manifestations. However, post-transplant mortality rate was relatively high in our center. Diarrhea, growth retardation, and steatosis are unique post-transplant complications in these patients. The rate of post-transplant steatosis and steatohepatitis in patients with liver biopsy in our study was $30 \%$, with a significant difference from previous studies.
\end{abstract}

Keywords: Intrahepatic Cholestasis, Liver, Transplantation, Steatosis, Steatohepatitis, Diarrhea, Growth Retardation, Normal Gamma-Glutamyl Transferase

\section{Background}

Cholestatic diseases are among the most serious liver disorders in infancy and childhood. Cholestasis is defined as defect of normal bile flow and is classified into extrahepatic cholestasis and intrahepatic cholestasis. Progressive familial intrahepatic cholestasis (PFIC) is an autosomal recessive disorder of childhood in which cholestasis usually presents in the infancy or first year of life and causes to liver failure at ages usually varying from infancy to adolescence $(1,2)$.

Historically, based on clinical findings, laboratory data, genetic defect, and liver biopsy, three types of PFIC were explained. PFIC type 1, or Byler's disease, is characterized by mutations of the ATP8B1 gene, which encodes the FIC 1 protein. PFIC type 2 is caused by mutations in the $\mathrm{ABCB} 11$ gene that lead to the decrease or absence of functional bile salt export pump (BSEP) expression. PFIC type 3 is caused by the mutations of the $\mathrm{ABCB} 4$ gene contribute to downregulation of the multidrug resistance class 3 glycoprotein. Currently, new types of this disease have been introduced. The mutations of TJP2 gene with loss of function of the tight junction protein 2 protein lead to PFIC type 4 , and PFIC type 5 is caused by the mutations of the NR1H4 gene, which encodes an essential transcription factor for 
bile acid homeostasis, farnesoid $\mathrm{X}$ receptor. A newly explained type of PFIC is related to a mutation in the MYO5B gene, critical for the normal trafficking of transporters and epithelial cell polarization (3-7).

PFIC is a syndrome in which patients develop severe cholestasis, advancing to the liver failure before adulthood. It has general clinical features, including jaundice, severe pruritus, and hepatomegaly. Growth retardation is also another clinical presentation in some types. Extrahepatic findings have been reported in PFIC type 1, such as short stature, diarrhea, sensorineural deafness, pancreatitis, and liver fatty change (2, 8-10). Also, neurological and respiratory symptoms are reported in PFIC type 4. Serum gamma-glutamyl transferase (GGT) activity is low-to-normal in most PFIC types except type $3(6,7)$. Histopathological findings in the liver biopsy of PFIC patients include bland centrilobular canalicular cholestasis, lobular fibrosis with acinar or pseudo-rosette formation, and variable degrees of giant cell transformation. Ductular reaction is seen in PFIC type 3 and 5. Over time, there is progression to micronodular cirrhosis $(6,7,11,12)$.

In the management of patients with PFIC, medical and surgical treatments play prominent roles. Currently, liver transplantation (LT) is the final treatment option available for PFIC when other treatments are unsuccessful $(6,12,13)$. An unwanted outcome of LT in patients with PFIC type 1 is the potential exacerbation of extrahepatic manifestations like diarrhea and short stature $(14,15)$, and diarrhea is often associated with steatosis on liver biopsy $(8,14,16)$. Post-LT steatosis is also reported in PFIC type $5(6,17)$. Few reports have discussed post-transplant liver steatosis and steatohepatitis in patients with PFIC $(8,16)$.

\section{Objectives}

In this study, we evaluated a large population of PFIC patients with normal GGT who had undergone LT within 17 years in a single-center, namely Shiraz Transplant Center, in Iran. We investigated the pre-and post-transplant clinical, paraclinical, and histopathological findings with emphasis on post-transplant development of steatosis and steatohepatitis.

\section{Methods}

\subsection{Study Population}

Between March 2000 and March 2017,133 patients with PFIC underwent LT in Shiraz Transplant Center, the only and major pediatric LT center in Iran. In our center, genetic testing for confirmation of PFIC was not performed due to both unavailability and high cost for patients. Therefore, the diagnosis of PFIC was based on these criteria: (i) Clinical manifestations including a history of chronic cholestasis with jaundice, pruritus, and hepatomegaly after ruling out other causes of childhood cholestasis such as neonatal hepatitis, biliary atresia, metabolic disorders, paucity of intrahepatic bile duct, biliary obstruction, and cholangiopathic disorders (ii) laboratory findings including high alkaline phosphatase and normal or low GGT, and (iii) liver histopathology and immunohistochemical study if needed. PFIC type 3 patients were not included in our study because of exclusion of high GGT patients. LT was performed due to severe liver failure, severe pruritus or severe growth retardation (defined as weight and height below the third percentile for age and sex), and failure of biliary diversion. The patients with missed file data and poor follow-up and death before one month after transplantation were excluded from post-transplant evaluation.

\subsection{Data Collection}

We examined the records of patients for these variables: Demographic data, date of LT, type of allograft, weight on the transplant day, history of pre-transplant biliary diversion operation, pre-transplant clinical manifestations, post-transplant clinical manifestations and complications, post-transplant immunosuppression therapy protocol, post-transplant laboratory data and liver histopathological findings, and date and cause of death.

\subsection{Histopathological Evaluation}

In our center, a post-transplant liver biopsy was taken when a progressive increase in the liver enzyme level was observed. Liver biopsies were evaluated by one experienced pathologist on hematoxylin-eosin, reticulin and Masson trichrome stains. Histopathological assessment of liver biopsies with steatosis and steatohepatitis was graded based on Brunt's classification $(18,19)$.

\subsection{Immunosuppressive Protocol}

Post-transplant immunosuppressive therapy was started by methylprednisolone; Tacrolimus was added on the second post-transplant day. As needed in other immunosuppressive drugs, mycophenolate mofetil is our choice. Biopsy-proven acute rejection was treated with i.v. methylprednisolone, followed by a three-day regimen of tapering.

\subsection{Study Design for Evaluation of Post-transplant Steatosis}

We classified the patients with post-transplant liver biopsy into two groups: (1) patients with steatosis and steatohepatitis confirmed by histopathological evaluation 
and (2) patients with no steatosis or steatohepatitis in liver biopsy. Then, the demographic data, pre-and posttransplant clinical manifestations, laboratory findings, and post-transplant complications were compared with each other.

\subsection{Statistical Analysis}

Statistical analyses were done using SPSS 25. Data are presented as mean \pm SD. The Mann-Whitney $U$ test was used for analysis. A P value of less than 0.05 was taken to be significant.

\section{Results}

Between March 2000 and March 2017, 133 PFIC patients with normal GGT underwent LT in Shiraz Transplant Center, the only pediatric liver transplant center in Iran. Of 133 patients, 13 had missed file data and poor follow-up and were excluded from the study. Also, nine patients died before one month of transplantation, so we evaluated only pre-transplant data and the cause of death for them. Then, 111 PFIC patients with normal GGT that had undergone LT were included in our study.

\subsection{Demographic Data and Pre-transplant Clinical Findings}

The mean age at the time of admission was $39 \pm 54$ (range 1-240) months. Besides, 72 (60\%) patients were boys and $48(40 \%)$ were girls with a male/female ratio of 1.5 . The mean weight at the time of admission was $12.2 \pm$ $13.6 \mathrm{~kg}$ (range 5-90). Also, 15 (12.5\%) patients underwent pre-transplant biliary diversion operation. The most common clinical manifestations were jaundice and pruritus. Growth retardation was detected in 92 (76.6\%) patients and pre-transplant diarrhea in 51 (42.5\%) patients.

\subsection{Post-transplant Clinical and Laboratory Findings}

In this study, 69 (57.5\%) patients were transplanted from deceased donors and 51 (42.5\%) patients from living related donors. Transplantations from living-related donors were from the mother, father, uncle, and aunt in 32 (26.7\%), 16 (13.3\%), two (1.6\%), and one (0.9\%) patients, respectively. Infection was the most common complication. Growth retardation was seen in 35 (31.5\%) patients and diarrhea in 41 (36.9\%) of them. Table 1 shows the distribution of pre-and post-transplant diarrhea, growth retardation, and steatosis/steatohepatitis in all patients. Diarrhea was relieved after transplantation in 31 (27.9\%) patients, did not change in 17 (15.3\%) patients, and developed de novo in 24 (21.6\%) patients. Also, growth retardation was relieved after transplantation in $52(46.8 \%)$ patients, did not change in 33 (29.7\%) of them, and developed de novo in two (1.8\%) patients. Both diarrhea and growth retardation were decreased after LT; 48 (43.2\%) patients with diarrhea decreased to 41 (36.9\%) patients and 85 (76.6\%) patients with growth retardation to 35 (31.5\%) patients. Of all 120 PFIC patients with normal GGT, 35 (29.1\%) patients died post-transplant, and 85 (70.9\%) were alive till the time of this study. Nine (7.5\%) patients died one month after LT due to sepsis (six patients), portal vein thrombosis (two patients), and unknown cause (one patient).

\subsection{Histopathological Evaluation After LT}

In this study, 74 post-transplant liver biopsies were taken from 50 (45\%) patients due to the significant increase in liver enzymes. The most common histopathological findings are acute rejection (44\%), steatosis and steatohepatitis (30\%), and extrahepatic bile duct obstruction (20\%). We had 15 (30\%) PFIC patients with steatosis or steatohepatitis in post-transplant liver biopsies, five (10\%) of whom had macrovesicular steatosis alone and 10 (20\%) had steatohepatitis.

\subsection{Patients With Post-transplant Steatosis/Steatohepatitis}

There were 15 patients within this group, and the demographic and other characteristics are presented in Table 2. Growth retardation was presented in seven patients and diarrhea in eight patients. Six patients had diarrhea, growth retardation, and steatosis together (Table 1). The time of post-transplant liver biopsy was $291 \pm 382$ days (range: 4-1387 days) after transplantation. Table 3 shows laboratory findings at the time of liver biopsy. The preand post-transplant clinical data, complications, outcome, cause, and date of death are presented in Table 4. Twentysix liver biopsies were taken from these patients; five (10\%) patients had macrovesicular steatosis alone, and 10 (20\%) had steatohepatitis. Eight patients had mild steatohepatitis, and two of them showed moderate steatohepatitis. The percentage and type of macrovesicular steatosis, nonalcoholic fatty liver disease (NAFLD) activity score (NAS), degree of fibrosis, and serial changes during the time are displayed in detail in Table 5. Seven out of 15 patients showed small-droplet macrovesicular steatosis; two patients showed moderate steatohepatitis and none of them showed severe steatohepatitis. Besides, NAS was 4,5 , and 6 in one, seven, and two of them, respectively. Nine patients with steatohepatitis showed mild fibrosis (stage I or II), and only one showed moderate bridging fibrosis (stage III). None of these patients showed severe fibrosis, and the cause of death in none of them was steatohepatitis.

\subsection{Patients Without Post-transplant Steatosis/Steatohepatitis}

There were 35 patients within this group, with demographic and other characteristics presented in Table 2. 


\begin{tabular}{|c|c|c|c|}
\hline Symptoms & Pre-transplant & Post-transplant & Number, \% \\
\hline \multirow{4}{*}{ Diarrhea } & Present & Absent & $31,27.9$ \\
\hline & Present & Present & $17,15.3$ \\
\hline & Absent & Present & $24,21.6$ \\
\hline & Absent & Absent & $39,35.1$ \\
\hline \multirow{4}{*}{ GR } & Present & Absent & $52,46.8$ \\
\hline & Present & Present & $33,29.7$ \\
\hline & Absent & Present & $2,1.8$ \\
\hline & Absent & Absent & $24,21.6$ \\
\hline \multirow{2}{*}{ Diarrhea and GR } & \multicolumn{2}{|c|}{ Both present in pre-transplant } & $37,33.3$ \\
\hline & \multicolumn{2}{|c|}{ Both present in post-transplant } & $21,18.9$ \\
\hline \multirow{3}{*}{$\begin{array}{l}\text { Diarrhea, growth retardation, } \\
\text { and steatosis }\end{array}$} & \multicolumn{2}{|c|}{ Diarrhea and steatosis present in post-transplant } & $8,7.2$ \\
\hline & \multicolumn{2}{|c|}{ GR and steatosis present in post-transplant } & $7,6.3$ \\
\hline & \multicolumn{2}{|c|}{ Diarrhea, GR, and steatosis present in post-transplant } & $6,5.4$ \\
\hline
\end{tabular}

Abbreviation: GR, growth retardation.

Table 2. Demographic and Other Characteristics of Groups with and Without Steatosis/Steatohepatitis

\begin{tabular}{|c|c|c|c|}
\hline & Steatosis/Steatohepatitis Group & No Steatosis/Steatohepatitis Group & PValue \\
\hline Number & 15 & 35 & - \\
\hline Age (mo) & & & 0.25 \\
\hline Mean \pm SD & $57 \pm 36$ & $70 \pm 56.7$ & \\
\hline Range & $11-134$ & $12-228$ & \\
\hline $\mathrm{M} / \mathrm{F}$ ratio & 0.87 & 1.91 & 0.2 \\
\hline Weight (kg) & & & 0.45 \\
\hline Mean \pm SD & $14.1 \pm 5.9$ & $17.2 \pm 11.8$ & \\
\hline Range & $7-27$ & $7-55$ & \\
\hline Type of allograft, No. (\%) & & & 0.15 \\
\hline Deceased & $11(73.3)$ & $18(51.4)$ & \\
\hline Living & $4(26.7)$ & $17(48.6)$ & \\
\hline History of pre-transplant biliary diversion operation, No. (\%) & $3(20)$ & $0(0)$ & Not reliable \\
\hline Death, No. (\%) & $10(66.6)$ & $9(25.7)$ & 0.02 \\
\hline \multicolumn{4}{|l|}{ Lab data in 1-2 months post-transplant, Mean \pm SD } \\
\hline INR & $1.3 \pm 0.45$ & $1.2 \pm 0.2$ & 0.13 \\
\hline $\operatorname{Albumin}(\mathrm{g} / \mathrm{dL})$ & $3.5 \pm 0.82$ & $3.6 \pm 0.9$ & 0.04 \\
\hline $\operatorname{AST}(\mathrm{U} / \mathrm{L})$ & $390 \pm 735$ & $71.6 \pm 57.8$ & 1.1 \\
\hline $\operatorname{ALT}(\mathrm{U} / \mathrm{L})$ & $257 \pm 373$ & $95.7 \pm 77.2$ & 1.5 \\
\hline $\operatorname{ALP}(\mathrm{U} / \mathrm{L})$ & $619 \pm 392$ & $747 \pm 639$ & 0.47 \\
\hline GGT $(\mathrm{U} / \mathrm{L})$ & $93 \pm 156$ & $52 \pm 71$ & 0.6 \\
\hline Total Bilirubin (mg/dL) & $1.4 \pm 1.6$ & $1.6 \pm 2$ & 0.24 \\
\hline
\end{tabular}

Abbreviations: INR, international normalized ratio; AST, aspartate transaminase; ALT, alanine transaminase; ALP, alkaline phosphatase; GGT, gamma-glutamyl transferase. 
Table 3. Laboratory Data in Patients with Steatosis and Steatohepatitis at the Time of Liver Biopsies (15 Patients).

\begin{tabular}{lccc|}
\hline Lab Test (unit) & Mean \pm SD & Minimum & Maximum \\
\hline INR & $1.8 \pm 1.1$ & 1 & 4.5 \\
\hline Albumin (g/dL) & $3.6 \pm 0.7$ & 2.6 & 5.3 \\
\hline AST (U/L) & $192 \pm 296$ & 47 & 1371 \\
\hline ALT (U/L) & $224 \pm 184$ & 38 & 735 \\
\hline ALP (U/L) & $623 \pm 482$ & 197 & 2161 \\
\hline Total bilirubin $(\mathbf{m g} / \mathbf{d L})$ & $2.2 \pm 2.9$ & 0.2 & 11.2 \\
\hline Direct bilirubin $(\mathbf{m g} / \mathbf{d L})$ & $1.1 \pm 1.4$ & 0.1 & 4.5 \\
\hline
\end{tabular}

Abbreviations: INR, international normalized ratio; AST, aspartate transaminase; ALT, alanine transaminase; ALP, alkaline phosphatase.

Growth retardation was found in nine patients and diarrhea in 12 patients. The time of post-transplant liver biopsy was $469 \pm 832$ days (range: 1-3005 days) after transplantation. The most common post-transplant histopathological findings consisted of acute rejection (45.7\%), extrahepatic biliary obstruction (28.5\%), acute cholestasis (17.1\%), and chronic rejection (14.2\%).

4.6. Comparison Between Patients with and Without Posttransplant Steatosis/Steatohepatitis

Statistical analysis between the two groups based on age, gender, weight, allograft type, history of pretransplant biliary diversion operation, death, and laboratory findings (Table 2 ) showed significant difference between two groups in death rate $66.6 \%$ in group with steatosis/steatohepatitis versus $25.7 \%$ in other group, $\mathrm{P}$ value: 0.02 ).

\section{Discussion}

In this study, we evaluated a single-center large population of PFIC patients with normal GGT who had undergone LT within 17 years in Shiraz Transplant Center in Iran. Also, this is the largest single-center living related donation for PFIC.

PFIC is a liver disorder, firstly described by Clayton et al. in 1965 as Byler disease (20). PFIC is the cause of neonatal cholestasis in $10-15 \%$ of the cases and $10-5 \%$ of children requiring LT. Jaundice and pruritus are an important clinical signs in all forms of PFIC (2-4). Also, in our study, the most common clinical manifestations were jaundice and pruritus.

Treatment of PFIC is composed of surgical and nonsurgical options. In all types of PFIC, medical therapy is the first line of treatment. The goals are to improve the nutritional status, alleviate pruritus, treat complications of chronic liver disease, and correct vitamin deficiencies. Ursodeoxycholic acid is the most commonly used drug for pruritus $(4,6,7,21,22)$. Non-transplant surgical interventions including partial external biliary diversion, ileal exclusion, and partial internal biliary diversion have significantly improved the outcome of PFIC patients. The biliary diversion procedures delayed or prevented the need for LT. They are indicated in non-cirrhotic children with cholestasis, low GGT, and severe pruritus. Partial external biliary diversion is an older common technique, but the permanent stoma is the disadvantage of it. On the other hand, partial internal biliary diversion as a new method has lower morbidity due to the absence of stoma $(23,24)$. LT is now available as the final definitive treatment for PFIC; it reverses many of the consequences of chronic liver disease. Several series have been reported the results of LT for PFIC in which patient survival and graft survival rates were $85.2 \%$ and $76.6 \%$, respectively (12). LT can lead to the relief of cholestasis and pruritus in these patients. The proper time of transplantation in PFIC patients is still debatable (14). Unlike in PFIC type 2, early transplantation in PFIC type 1 is controversial (12).

Pre-transplant management of PFIC patients in our center depends on the intensity of clinical symptoms, especially pruritus and degree of liver fibrosis. At first, for the relief of pruritus, medical therapy is started from low to maximum dose by drugs such as ursodeoxycholic acid, rifampin, phenobarbital, cholestyramine, and naltrexone. Biliary diversion is done for non-cirrhotic patients that do not respond to medical therapy. For cirrhotic patients and those with biliary diversion and unrelieved symptoms, LT is indicated.

The usual biliary diversion method in our center is a partial internal biliary diversion. A recent study in our center about the effect of partial internal biliary diversion showed a significant decrease in sleep disturbance and pruritus after the operation. This operation is a beneficial approach in non-cirrhotic children with PFIC (23). In our study, 15 (12.5\%) patients had a previous history of biliary diversion operation; however, our center is a referral center where the patients at the end-stage period are referred for LT from all around the country or even neighboring countries; the precise data from the operation were not available for more evaluation.

Although LT can result in the relief of symptoms related to chronic liver disease, the post-transplant outcomes are varied. Like LT for other liver diseases, various complications have also been recorded, such as rejection and infection after transplantation for PFIC that do not seem to happen in increased frequency $(12,25)$. In addition to these complications, some others are particularly associated with PFIC. In cases of PFIC type 1, LT can 


\begin{tabular}{|c|c|c|c|c|c|c|c|c|c|c|c|c|}
\hline \multirow[t]{2}{*}{ Patient } & \multirow{2}{*}{$\begin{array}{l}\text { Simple Steatosis or } \\
\text { Steatohepatitis }\end{array}$} & \multirow[t]{2}{*}{$\operatorname{Age}(\mathrm{mo})$} & \multirow[t]{2}{*}{ Gender } & \multirow[t]{2}{*}{ Allograft } & \multirow{2}{*}{$\begin{array}{c}\text { History of } \\
\text { Pre-transplant } \\
\text { Biliary Diversion }\end{array}$} & \multicolumn{2}{|c|}{ Pre-transplant } & \multicolumn{2}{|c|}{ Post-transplant } & \multirow[t]{2}{*}{ Outcome } & \multirow[t]{2}{*}{ Cause of Death } & \multirow{2}{*}{$\begin{array}{l}\text { Interval of Death to } \\
\text { Transplant (days) }\end{array}$} \\
\hline & & & & & & Diarrhea & GR & Diarrhea & GR & & & \\
\hline 1 & Simple steatosis & 42 & M & L & No & Present & Present & Present & Present & Died & Sepsis & 35 \\
\hline 2 & Simple steatosis & 11 & $\mathrm{~F}$ & L & No & Absent & Absent & Present & Absent & Died & Unknown & 510 \\
\hline 4 & Simple steatosis & 42 & F & D & No & Present & Present & Present & Present & Died & Sepsis & 330 \\
\hline 5 & Simple steatosis & 52 & M & D & No & Absent & Absent & Absent & Present & Died & Sepsis & 150 \\
\hline 6 & Steatohepatitis & 24 & M & L & No & Absent & Absent & Present & Present & Died & Sepsis & 450 \\
\hline 7 & Steatohepatitis & 72 & M & D & No & Present & Present & Present & Present & Died & Unknown & 660 \\
\hline 8 & Steatohepatitis & 132 & F & D & No & Present & Present & Absent & Present & Alive & - & - \\
\hline 9 & Steatohepatitis & 134 & F & D & No & Present & Absent & Present & Present & Alive & . & . \\
\hline 11 & Steatohepatitis & 30 & M & D & No & Absent & Absent & Present & Present & Alive & - & - \\
\hline 12 & Steatohepatitis & 60 & $\mathrm{~F}$ & $\mathrm{D}$ & No & Present & Present & Absent & Present & Died & Sepsis & 1440 \\
\hline 13 & Steatohepatitis & 30 & $\mathrm{~F}$ & D & No & Present & Present & Present & Present & Died & Sepsis & 960 \\
\hline 14 & Steatohepatitis & 66 & M & D & Yes & Present & Absent & Present & Present & Died & Biliary disease & 870 \\
\hline 15 & Steatohepatitis & 31 & M & L & Yes & Absent & Absent & Present & Present & Died & Sepsis & 120 \\
\hline
\end{tabular}

be associated with an increase in liver steatosis and extrahepatic manifestations, especially chronic watery diarrhea and growth retardation. However, the severity and manifestation of these symptoms are unpredictable $(8,12)$. The exacerbation of diarrhea after LT in patients with PFIC type 1 is a serious problem and may impair the quality of life $(15,26)$. Aydoghu et al. reported 19 patients of PFIC with LT, four of whom developed post-transplant diarrhea (14). In our study, the frequency of diarrhea after LT decreased relatively ( $43.2 \%$ pre-transplant versus $36.9 \%$ posttransplant); however, this reduction was not significant. Also, we had 24 (21.6\%) patients that developed de novo diarrhea and 17 (15.3\%) patients who did not relieve after LT. Thus, post-transplant diarrhea was still an important complication in our patients. Medical therapy with cholestyramine could relieve this symptom in our experience. The rate of growth retardation was reduced significantly $(76.6 \%$ pre-transplant versus $31.5 \%$ post-transplant) after LT in our study. Also, we had only two (1.8\%) patients that developed de novo growth retardation after LT.

Post-transplant liver steatosis and steatohepatitis can also be identified in patients with PFIC type 1 and 5. Table 6 shows the previous studies in which liver steatosis developed as a post-transplant complication in patients with PFIC. Miyagawa-Hayashino et al. (8) reported the largest previous study that specifically focused on post-transplant steatohepatitis with 11 PFIC type 1 patients, in eight of whom post-transplant hepatic macrovesicular steatosis was developed, and seven progressed to steatohepatitis. Six showed bridging fibrosis, with two of them progress- ing to cirrhosis. The rate of steatosis and steatohepatitis in our study was 30\% in patients with post-transplant liver biopsy, which is lower than in previous studies (the largest by Miyagawa-Hayashino et al. (8) about 73\%). The population in our study was larger than in the previous ones, but the PFIC patients were not subtyped by genetic study. Also, another important difference with previous studies was the outcome and degree of fibrosis in patients with steatosis and steatohepatitis. Miyagawa-Hayashino et al. reported six (54.5\%) PFIC type1 patients with bridging fibrosis, and two (18.1\%) of whom developed cirrhosis (8). However, in our study, only one (2\%) patient showed bridging fibrosis, and none progressed to cirrhosis. Also, none of them led to re-transplantation or death due to steatohepatitis. In our center, we prescribed vitamin $\mathrm{E}$ as an antioxidant for PFIC patients with steatosis. As mentioned, we had 15 patients with pre-transplant biliary diversion, three (20\%) of whom showed steatosis or steatohepatitis. It is lower compared to the rate of steatosis and steatohepatitis in the whole population. The rate of death in patients with steatosis/steatohepatitis was relatively high in our study although the cause of death was, in most cases, sepsis and was not related to steatosis. This relatively high rate of death due to sepsis in this population needs more detailed evaluation in our center.

Some studies have reported the co-occurrence of posttransplant diarrhea and steatosis in PFIC patients $(8,25-$ 29). In our study, diarrhea, and steatosis co-occurred in eight (7.2\%) patients. Aydogdu et al. (14) have shown that LT increases the growth rate in patients with PFIC due to 


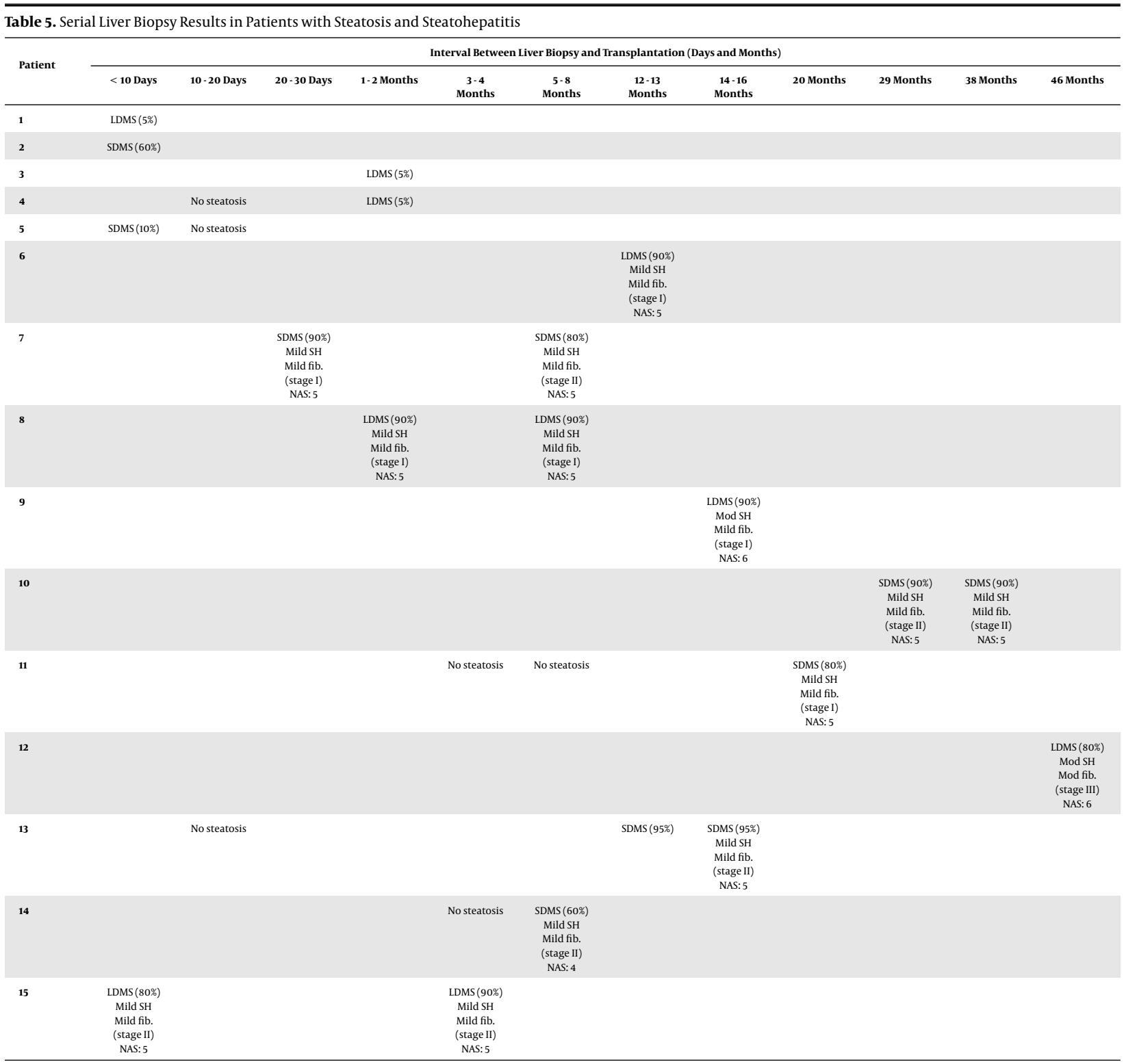

Abbreviations: LDMS, large droplet macrovesicular steatosis; SDMS, small droplet macrovesicular steatosis; Mod, moderate; SH, steatohepatitis; NAS, NAFLD activity score; fib., fibrosis.

increased vitamin D absorption, production of insulinlike growth factors, a decrease of portal hypertension, and increased quality of life. Also, in our study, the rate of growth retardation decreased after LT. The co-occurrence of growth retardation and steatosis was $6.3 \%$ (seven patients). Also, the occurrence of diarrhea, growth retardation, and steatosis was 5.4\% (six patients).

The present study had certain limitations and strengths. The first limitation was that genetic study was not available for most of the patients, so we diagnosed PFIC according to the combination of clinical, laboratory, and pathological findings. Second, standard deviation scores of weight and height at the time of transplant and given intervals after transplant were not available. Third, we excluded the PFIC patients with high GGT from our study. However, this study is by far the largest experience with LT for PFIC patients, and we demonstrated important differences from what has been published to date.

In conclusion, the most common clinical manifestations of PFIC patients with normal GGT were jaundice and pruritus. LT is a final treatment for these patients with cirrhotic liver or patients not responding to medical therapy and biliary diversion, and it can relieve most clinical manifestations. However, the post-transplant mortality rate was 


\begin{tabular}{|c|c|c|c|}
\hline Study & Number of PFIC Patients (Type) & Hepatic Steatosis and Steatohepatitis & Hepatic Fibrosis (Degree) \\
\hline Lykavieris et al. (26) & 2 (type 1 ) & 2 (mild to severe steatosis) & 2 (mild) \\
\hline Bassas et al. (27) & $13(\mathrm{~N} / \mathrm{D})$ & 1 (moderate to severe steatosis) & $\mathrm{N} / \mathrm{D}$ \\
\hline $\begin{array}{l}\text { Miyagawa-Hayashino et al. (8) and Hori et } \\
\text { al. (28) }\end{array}$ & 11 (type 1 ) & $\begin{array}{l}1 \text { (moderate to severe steatosis), } 7 \\
\text { (steatohepatitis) }\end{array}$ & 9 (stage III and IV) \\
\hline Nicastro et al. (16) & 1 (type 1 ) & 1 (severe steatohepatitis) & 1 (mild) \\
\hline Berumen et al. (25) & 1 (type 1 ) & 1 (moderate steatosis) & N/D \\
\hline Liu et al. (29) & 3 (type 1) & 2 (moderate to severe steatohepatitis) & 1 (stage III) \\
\hline Gomez-Ospina et al. (17) & 4 (type 5) & 4 (progressive steatosis) & $\mathrm{N} / \mathrm{D}$ \\
\hline Current study & $111(\mathrm{~N} / \mathrm{D})$ & 5 (mild to severe steatosis), 10 (steatohepatitis) & 10 (9 stage I-II, 1 stage III) \\
\hline
\end{tabular}

Abbreviation: N/D, not determined.

relatively high (29.1\%), and the most common cause was sepsis. The rate of post-transplant steatosis and steatohepatitis in patients with liver biopsy in our study was $30 \%$. Also, the rate of moderate and severe fibrosis was low. The rate of growth retardation was reduced significantly after LT, and the frequency of diarrhea decreased relatively. It is important to pay attention to these complications in posttransplant management of PFIC patients.

\section{Acknowledgments}

The present article was extracted from the thesis written by Dr. Maryam Poostkar and was financially supported by Shiraz University of Medical Sciences grants No 15080. The authors would like to thank Shiraz University of Medical Sciences, Shiraz, Iran, the Center for Development of Clinical Research of Nemazee Hospital, and Dr. Nasrin Shokrpour for editorial assistance.

\section{Footnotes}

Authors' Contribution: MHA designed the study, revised the manuscript, carried out histopathologic evaluation. SMD designed the study, revised the manuscript. MP did the data collection and contributed to the draft of manuscript. SAM was involved in the clinical evaluation of the patients and revised the manuscript.

Conflict of Interests: There is no conflict of interest.

Ethical Approval: This study was approved by Shiraz University of Medical Sciences Ethics Committee.

Funding/Support: This study was supported by Shiraz University of Medical Sciences Vice-Chancellor of Research Grant (15080) awarded to MHA.

Informed Consent: This is a retrospective study.

\section{References}

1. Giovannoni I, Callea F, Bellacchio E, Torre G, De Ville De Goyet J, Francalanci P. Genetics and Molecular Modeling of New Mutations of Familial Intrahepatic Cholestasis in a Single Italian Center. PLoS One. 2015;10(12). e0145021. doi: 10.1371/journal.pone.0145021. [PubMed: 26678486]. [PubMed Central: PMC4683058].

2. Jacquemin E. Progressive familial intrahepatic cholestasis. Clin Res Hepatol Gastroenterol. 2012;36 Suppl 1:S26-35. doi: 10.1016/S22107401(12)70018-9. [PubMed: 23141890].

3. Hori $\mathrm{T}$, Nguyen $\mathrm{JH}$, Uemoto $\mathrm{S}$. Progressive familial intrahepatic cholestasis. Hepatobiliary Pancreat Dis Int. 2010;9(6):570-8. [PubMed: 21134824].

4. Srivastava A. Progressive familial intrahepatic cholestasis. J Clin Exp Hepatol. 2014;4(1):25-36. doi: 10.1016/j.jceh.2013.10.005. [PubMed: 25755532]. [PubMed Central: PMC4017198].

5. Hori T, Egawa H, Miyagawa-Hayashino A, Yorifuji T, Yonekawa Y, Nguyen $\mathrm{JH}$, et al. Living-donor liver transplantation for progressive familial intrahepatic cholestasis. World J Surg. 2011;35(2):393-402. doi: 10.1007/s00268-010-0869-6. [PubMed: 21125272].

6. Amirneni S, Haep N, Gad MA, Soto-Gutierrez A, Squires JE, Florentino RM. Molecular overview of progressive familial intrahepatic cholestasis. World J Gastroenterol. 2020;26(47):7470-84. doi: 10.3748/wjg.v26.i47.7470. [PubMed: 33384548]. [PubMed Central: PMC7754551].

7. Bull LN, Thompson RJ. Progressive Familial Intrahepatic Cholestasis. Clin Liver Dis. 2018;22(4):657-69. doi: 10.1016/j.cld.2018.06.003. [PubMed: 30266155].

8. Miyagawa-Hayashino A, Egawa H, Yorifuji T, Hasegawa M, Haga $H$, Tsuruyama T, et al. Allograft steatohepatitis in progressive familial intrahepatic cholestasis type 1 after living donor liver transplantation. Liver Transpl. 2009;15(6):610-8. doi: 10.1002/lt.21686. [PubMed: 19479804].

9. Davit-Spraul A, Gonzales E, Baussan C, Jacquemin E. Progressive familial intrahepatic cholestasis. Orphanet J Rare Dis. 2009;4:1. doi: 10.1186/1750-1172-4-1. [PubMed: 19133130]. [PubMed Central: PMC2647530].

10. Bull LN, Carlton VE, Stricker NL, Baharloo S, DeYoung JA, Freimer $\mathrm{NB}$, et al. Genetic and morphological findings in progressive familial intrahepatic cholestasis (Byler disease [PFIC-1] and Byler syndrome): evidence for heterogeneity. Hepatology. 1997;26(1):155-64. doi: 10.1002/hep.510260121. [PubMed: 9214465].

11. Morotti RA, Suchy FJ, Magid MS. Progressive familial intrahepatic cholestasis (PFIC) type 1, 2, and 3: a review of the liver pathology findings. Semin Liver Dis. 2011;31(1):3-10. doi: 10.1055/s-0031-1272831. [PubMed: 21344347]. 
12. Mehl A, Bohorquez H, Serrano MS, Galliano G, Reichman TW. Liver transplantation and the management of progressive familial intrahepatic cholestasis in children. World J Transplant. 2016;6(2):27890. doi: 10.5500/wjt.v6.i2.278. [PubMed: 27358773]. [PubMed Central: PMC4919732].

13. Englert C, Grabhorn E, Richter A, Rogiers X, Burdelski M, Ganschow R. Liver transplantation in children with progressive familial intrahepatic cholestasis. Transplantation. 2007;84(10):1361-3. doi: 10.1097/01.tp.0000282869.94152.4f. [PubMed: 18049123].

14. Aydogdu S, Cakir M, Arikan C, Tumgor G, Yuksekkaya HA, Yilmaz $\mathrm{F}$, et al. Liver transplantation for progressive familial intrahepatic cholestasis: clinical and histopathological findings, outcome and impact on growth. Pediatr Transplant. 2007;11(6):634-40. doi: 10.1111/j.1399-3046.2007.00722.x. [PubMed: 17663686].

15. Egawa H, Yorifuji T, Sumazaki R, Kimura A, Hasegawa M, Tanaka K. Intractable diarrhea after liver transplantation for Byler's disease: successful treatment with bile adsorptive resin. Liver Transpl. 2002;8(8):714-6. doi: 10.1053/jlts.2002.34384. [PubMed:12149765].

16. Nicastro E, Stephenne X, Smets F, Fusaro F, de Magnee C, Reding R, et al. Recovery of graft steatosis and protein-losing enteropathy af ter biliary diversion in a PFIC 1 liver transplanted child. Pediatr Transplant. 2012;16(5):E177-82. doi: 10.1111/j.1399-3046.2011.01514.x. [PubMed: 21672103].

17. Gomez-Ospina N, Potter CJ, Xiao R, Manickam K, Kim MS, Kim KH et al. Mutations in the nuclear bile acid receptor FXR cause progressive familial intrahepatic cholestasis. Nat Commun. 2016;7:10713. doi: 10.1038/ncomms10713. [PubMed: 26888176]. [PubMed Central: PMC4759630]

18. Kleiner DE, Brunt EM. Nonalcoholic fatty liver disease: pathologic patterns and biopsy evaluation in clinical research. Semin Liver Dis. 2012;32(1):3-13. doi: 10.1055/s-0032-1306421. [PubMed: 22418883].

19. Brown GT, Kleiner DE. Histopathology of nonalcoholic fatty liver disease and nonalcoholic steatohepatitis. Metabolism. 2016;65(8):10806. doi: 10.1016/j.metabol.2015.11.008. [PubMed: 26775559]. [PubMed Central: PMC4889547].

20. Clayton RJ, Iber FL, Ruebner BH, McKusick VA. Byler disease. Fatal familial intrahepatic cholestasis in an Amish kindred. Am J Dis Child 1969;117(1):112-24. [PubMed: 5762004].

21. Shneider BL. Progressive intrahepatic cholestasis: mechanisms, diagnosis and therapy. Pediatr Transplant. 2004;8(6):609-12. doi: 10.1111/j.1399-3046.2004.00240.x. [PubMed: 15598335].

22. Melter M, Rodeck B, Kardorff R, Hoyer PF, Petersen C, Ballauff A, et al. Progressive familial intrahepatic cholestasis: partial biliary diversion normalizes serum lipids and improves growth in noncirrhotic patients. Am J Gastroenterol. 2000;95(12):3522-8. doi: 10.1111/j.15720241.2000.03370.x. [PubMed: 11151888].

23. Foroutan HR, Bahador A, Ghanim SM, Dehghani SM, Anbardar $\mathrm{MH}$, Fattahi MR, et al. Effects of partial internal biliary diversion on long-term outcomes in patients with progressive familial intrahepatic cholestasis: experience in 44 patients. Pediatr Surg Int. 2020;36(5):603-10. doi: 10.1007/s00383-020-04641-z. [PubMed: 32206891].

24. Gunaydin M, Tander B, Demirel D, Caltepe G, Kalayci AG, Eren E, et al. Different techniques for biliary diversion in progressive familial intrahepatic cholestasis. J Pediatr Surg. 2016;51(3):386-9. doi: 10.1016/j.jpedsurg.2015.08.011. [PubMed: 26382286].

25. Berumen J, Feinberg E, Todo T, Bonham CA, Concepcion W, Esquivel C. Complications following liver transplantation for progressive familial intrahepatic cholestasis. Dig Dis Sci. 2014;59(11):2649-52. doi: 10.1007/s10620-014-3220-5. [PubMed: 24879297].

26. Lykavieris P, van Mil S, Cresteil D, Fabre M, Hadchouel M, Klomp L, et al. Progressive familial intrahepatic cholestasis type 1 and extrahepatic features: no catch-up of stature growth, exacerbation of diarrhea, and appearance of liver steatosis after liver transplantation. $J$ Hepatol. 2003;39(3):447-52. doi: 10.1016/s0168-8278(03)00286-1. [PubMed: 12927934].

27. Bassas A, Chehab M, Hebby H, Al Shahed M, Al Husseini H, Al Zahrani $A$, et al. Living related liver transplantation in 13 cases of progressive familial intrahepatic cholestasis. Transplant Proc. 2003;35(8):3003-5. doi: 10.1016/j.transproceed.2003.10.047. [PubMed:14697961].

28. Hori T, Egawa H, Takada Y, Ueda M, Oike F, Ogura Y, et al. Progressive familial intrahepatic cholestasis: a single-center experience of livingdonor liver transplantation during two decades in Japan. Clin Transplant. 2011;25(5):776-85. doi: 10.1111/j.1399-0012.2010.01368.x. [PubMed: 21158920].

29. Liu Y, Sun LY, Zhu ZJ, Wei L, Qu W, Zeng ZG. Liver Transplantation for Progressive Familial Intrahepatic Cholestasis. Ann Transplant. 2018;23:666-73. doi: 10.12659/AOT.909941. [PubMed: 30250015]. [PubMed Central: PMC6248029]. 